\title{
MORPHOLOGICAL AWARENESS AND ITS CORRELATION WITH EFL READING COMPREHENSION OF SENIOR HIGH SCHOOL STUDENTS
}

\author{
Zulfadli A. Aziz ${ }^{a^{*}}$, Bukhari Daud ${ }^{b}$, Randila Tiayu Ismar ${ }^{c}$ \\ (a)zulfadli.aziz@unsyiah.ac.id; bukharidaud@unsyiah.ac.id; \\ ismar.randila@gmail.com) \\ Universitas Syiah Kuala, Banda Aceh \\ Jln. Teuku Nyak Arief Darussalam, Banda Aceh, Aceh, 23111
}

\begin{abstract}
This study investigates the correlation between morphological awareness and reading comprehension. It was conducted with a sample of 55 second-grade students from SMA (Senior High School) Laboratorium Unsyiah, Banda Aceh. The data measuring morphological awareness and reading comprehension were collected through a test of morphological awareness and the Florida comprehensive assessment test (FCAT) respectively. The Pearson product-moment correlation coefficient was determined using SPSS 20 software to explore the relationship between these variables. Based on the findings, the result from morphological awareness test showed that $85 \%$ of the students managed to answer the test satisfactorily. It was also revealed that the students were on reading Achievement Level 4. This indicates that the students answered many questions correctly, but they seemed to be troubled by questions with more challenging contents. The results also show that there was a significant relationship between morphological awareness and reading comprehension. The correlation was found to be 0.527 , with a significance level of 0.01 , which is classified as a moderate-level correlation. Finally, the findings of this study suggest the inclusion of morphological awareness while learning reading comprehension at schools.
\end{abstract}

Keywords: correlation, morphological awareness, reading comprehension

DOI: http://dx.doi.org/10.15639/teflinjournal.v30i1/121-136

*Corresponding author 
Reading is a source of knowledge, and it is undeniably important in the second language learning process. For this reason, developing reading comprehension skills is essential. To master reading comprehension, a learner needs to have some intellectual abilities. These intellectual abilities are what experts identify as factors affecting reading comprehension. Harvey and Goudvis (2007) conclude that there are three factors that affect reading comprehension. These are vocabulary development, sentence comprehension, and students' background knowledge. The first factor is vocabulary development. The reason for this is clear; in order to comprehend a text, firstly, a learner must understand the words contained in it. Most learners have trouble with reading comprehension because of their lack of understanding of the vocabulary. Therefore, by understanding the words used, learners will have a better understanding of the piece of writing. Besides vocabulary knowledge, sentence comprehension is also a core factor in reading comprehension. This is more complicated than vocabulary knowledge. Readers have the freedom to choose their preferred strategy to improve their comprehension. Monitoring, answering and generating questions, and summarizing are a few of the many strategies that can be used for this purpose. The last factor affecting reading comprehension is students' background knowledge. By having background knowledge, a learner will be able to comprehend a reading text more easily. This is because they will have an idea of what a text is about.

An important issue that might cause difficulty to second language learners in understanding reading texts is a lack of vocabulary (Schmitt, 2000). As Schmitt (2000) further points out, vocabulary is very important in achieving a certain level of reading comprehension. In a comprehensive study concerning the role of vocabulary mastery and reading comprehension, he found that native English speakers need at least 5,000 word families to be able to comprehend texts successfully. Word families refer to words that are related to each other in terms of meaning. Meanwhile, a second language learner needs to have at least 10,000 base words for academic purposes. This is where morphological awareness is believed to play a role in reading comprehension. As Kuo and Anderson (2006) suggest, morphological awareness is an important part of reading ability. It aids readers in translating and understanding unknown morphologically complex words. This result is in line with Carlisle's (2000) research, which found that readers with morphological awareness are better at reading comprehension than those without it. 
Morphological awareness is the awareness of and access to the meaning and structure of morphemes in relation to words (McBride-Chang,Wagner, Muse \& Chow, 2005). It is readers' ability to form new meanings and understanding from unknown complex words by processing these words into morphemes (Kuo \& Anderson, 2006). To put it simply, morphological awareness is the ability to identify and manipulate morphemes. It refers to learners' knowledge about morphologically complex words and their ability to form new meanings out of words (Carlisle, 1995). Using morphological awareness, learners are taught to disassemble complex words into morphemes (e.g. unhappiness $=u n+$ happy + ness $)$, to learn the meaning of roots and affixes (un- = prefix meaning not, happy $=$ feeling or showing pleasure, - ness $=$ forming nouns from adjectives), and to reassemble the meaningful parts into words with new meanings (uneasiness, unfairness, uncertainness). This disassembling-reassembling process is called morphological analysis.

Morphology and vocabulary are two factors that are related to each other. Vocabulary is part of morphology, while morphology itself is often described as an area in grammar that concerns the structure of words and the relationship between words that include morphemes. The lack of vocabulary mastery and morpheme analysis ability could prevent learners from understanding messages in the text, especially since $60-80 \%$ of new words found in academic reading texts are morphologically complex words. Because of this, the ability to analyze morphemes could help learners in comprehending text, considering that it would enable them to understand more vocabulary (Carlisle, 1995). Thus, it will be easier for students with this ability to comprehend a reading text.

To have the ability to manipulate the structure of words, one must apply one's knowledge of word-formation rules to interpret complex words correctly and to produce new word forms by oneself (Wang, Cheng \& Chen, 2006). Wang et al. (2006) further divide the skill of morphological awareness into four categories of ability which are acquired in a long and gradual process. These categories are identification, discrimination, interpretation, and manipulation. Identification refers to the ability possessed by learners to detect and recognize morphemes and complex words. Discrimination refers to the ability to differentiate morphemes from semantically and phonologically the same words. Interpretation means a standard that is used to evaluate learners' ability to make use of their compounding rules and derivational morphology knowledge to produce a correct meaning of a certain complex word. Lastly, 
manipulation is the ability possessed by learners to employ their knowledge of compounding rules and derivational morphology to compose morphemes and complex words in a certain context.

With the ability of manipulating word structure, it is highly possible that morphological awareness can be a potential strategy for learners in enhancing their reading comprehension. Berninger, Abbott, Nagy, and Carlisle (2010) and Jarmulowicz, Hay, Taran and Ethington (2008) have pointed this possibility as well. Jarmulowicz et al. (2008) report that morphological awareness grows and becomes a more important predictor after third grade and through the high school years. Berninger et al. (2010) also conducted a longitudinal study to see the growth of phonological awareness and morphological awareness. The study reported that different from phonological awareness, morphological awareness development peaked during fourth grade to sixth grade. However, this development still shows a rapid growth even after passing the sixth grade mark. The growth continues to develop throughout senior high school grade. In line with this growth, the correlation with reading comprehension is also growing. This is in opposite with phonological awareness. Phonological awareness becomes less important as learners grow and develop their literacy skills, thus, they recommended including morphological awareness in reading models.

A number of studies have been conducted with a goal of determining the relationship between morphological awareness and reading comprehension. Some of these recent studies have revealed that, aside from playing an important role in vocabulary knowledge, morphological awareness is also a significant contributor to reading comprehension (see Curinga, 2014; Deacon \& Kirby, 2004; Goodwin, Huggins, Carlo, August, \& Calderon, 2013; Kieffer \& Box, 2013; Kuo \& Anderson, 2006; Nagy, Berninger, \& Abbot, 2006). In a study conducted by Curinga (2014), morphological awareness was shown to have an impact on reading comprehension. However, this impact was only significant in a group with higher proficiency because they were seemingly more aware of the effect of morphological structure contribution to language than others in a group with lower proficiency. Kieffer, Biancarossa, and Mancila-Martinez (2013), after investigating both direct and indirect roles of morphological awareness in reading comprehension for Spanish-speaking language minority learners reading in English, found that morphological awareness had contributed to second-language reading comprehension. Their study further revealed that this contribution is mediated by reading vocabulary and passage fluency. Another study from Deacon, Kieffer and Laroche (2014) 
also showed a consistent result. Their research proved that morphological awareness facilitates support on reading comprehension and reading comprehension facilitates support on morphological awareness to some extent.

However, all of the mentioned studies above involved L1 or L2 students and ESL students. Very limited research so far has been done in a country where the students learn English as a foreign language. One of the few studies that have been done in EFL context is the one by Zhang and Koda (2013). Zhang and Koda (2013) conducted a research with 245 sixth graders who were reported to have received about 350 hours of formal EFL education in their school. The finding revealed that morphological awareness plays an important role in reading comprehension, including the awareness in compound aspect, (Zhang \& Koda, 2013, p. 911). One possible explanation, as also suggested by Nagy et al. (2006), is that the awareness of the word structure is critical in helping the students understand the complex words they encountered in reading text. Zhang, Koda and Sun (2014) examined the contribution of morphological awareness to reading comprehension of young Chinese EFL readers in China, and found that compound awareness contributed to reading comprehension within both Chinese and English.

Another researcher, Bae (2016), who measured the morphological awareness and reading comprehension of fifth and sixth grade EFL learners, found similar results. Morphological awareness is proven to have positive effects on reading comprehension. Chen and Schwartz (2018, p. 1692)also found that morphological awareness proved to "contribute to all literacy outcomes, including word reading, vocabulary, and reading comprehension".

Although there are numerous studies about morphological awareness and reading comprehension, studies on EFL adolescent learners are still limited as the majority of the previous studies focused on children. Not many studies deal with older groups of learners (middle- and high schoolers). The present study is also one of few studies which concern morphological awareness of Indonesian students.

From the above reviews, we believe that morphological awareness plays a significant role in reading comprehension and that morphological awareness is a cognitive skill that can help learners enhance their reading comprehension. Based on this reason, we aim to investigate the correlation between the morphological awareness and reading comprehension of senior high school students in Indonesian context. More specifically, it seeks to answer these two research questions: 
1. What are the students' levels of reading comprehension?

2. Is there any relationship between the students' morphological awareness and EFL reading comprehension ability?

While correlational study does not provide the cause and effect, it is a stepping stone to a further experimental study. The result of this research can provide some useful insights. Once the correlation is determined, it can be used to make a prediction. This prediction is fundamental as the base of the next research. In this case, once the correlation between morphological awareness and reading comprehension is determined, the researchers can then decide the next step to find the causal and effect of the correlation.

The results of the study can be used as a reference for teachers and learners to find a more effective technique in acquiring new vocabulary as well as enhancing reading comprehension. Although morphological awareness is not the only strategy that can be taught to improve students' reading comprehension, it is a potential learning strategy that can help students overcome their difficulties comprehending reading texts.

\section{METHOD}

This present study was conducted at Senior High School (SMA) Laboratorium Unsyiah. It is one of the prestigious schools in Banda Aceh, with excellent reputation in English, especially in the way the school has won many awards from English debate competitions. Despite the achievements made in the field of English, from a preliminary interview with the English teacher from this school, it was revealed that more than half of the students in the school are still struggling with their English learning.

Each grade in this school was divided into two departments, social science class and natural science class. The second grade students of SMA Laboratorium Unsyiah, with a total of 128 students, were the population of this study. There were four groups of students of the eleventh grade, namely X1 IPA 1, X1 IPA 2, X1 IPA 3, and X1 IPS 1. A total of 55 second-grade students from XI Science Class 1 and XI Science Class 3 participated in this research. The sample was chosen by random sampling.

In collecting the data, two kinds of tests were implemented as the instruments: a morphological awareness test and the Florida Comprehensive Assessment Test (FCAT). For the first part of the study, students were given a 
test on morphological awareness. This test was adopted from Nurhemida (2007), who adopted the test from the original version developed by McBrideChang et al. (2005). It combines a morpheme identification test and a morphological structural awareness test. There are 25 questions in total. The first five questions deal with morpheme identification. Each of these questions includes two pictures and two words. The students had to choose which picture correctly reflects the meaning of the word. The second task, the morphological structural awareness test, consists of 20 questions. In this task, students had to answer questions by manipulating the information provided in the example.

In the second part of the test, the FCAT proposed by Foresman (2001) was used. This test measures the comprehension and vocabulary aspects of reading. In this test, the students were provided with four different texts, with five multiple-choice questions for each text.

These tests were conducted on the same day and were divided into two parts. Since the participants were from two classes, each of the classes took the test on a different day. The procedures used to collect data from both classes were the same. In the first part, the students were tested on morphological awareness for 60 minutes. They were then given a 30 -minute break before they continued with the FCAT, which took about 60 to 70 minutes.

In order to answer the research questions regarding the students' levels of reading comprehension and whether or not there is a correlation between the students' morphological awareness and their reading comprehension ability, we referred to the five achievement level descriptions proposed by Foresman (2001). These levels are explained in Table 1.

\section{Table 1. FCAT Achievement Level Descriptions}

\begin{tabular}{ccl}
\hline $\begin{array}{c}\text { Achievement } \\
\text { Level }\end{array}$ & Score & \multicolumn{1}{c}{ Description } \\
\hline Level 5 & $81-100$ & $\begin{array}{l}\text { This student has success with most challenging content } \\
\text { on the FCAT. Scores at Level } 5 \text { mean that students can } \\
\text { answer most of the questions correctly, including } \\
\text { questions about the most challenging content. }\end{array}$ \\
\hline Level 4 & $61-80$ & $\begin{array}{l}\text { This student has success with challenging content on the } \\
\text { FCAT. Scores at Level 4 mean that students can answer } \\
\text { most of the questions correctly, but may have only partial } \\
\text { success with questions that reflect the most challenging }\end{array}$ \\
\hline
\end{tabular}




\begin{tabular}{ccl}
\hline $\begin{array}{c}\text { Achievement } \\
\text { Level }\end{array}$ & Score & \multicolumn{1}{c}{ Description } \\
\hline Level 3 & $41-60$ & $\begin{array}{l}\text { This student has partial success with challenging content } \\
\text { on the FCAT, but performance is inconsistent. Scores at } \\
\text { Level 3 mean that students can answer many of the test } \\
\text { questions correctly, but are generally less successful with } \\
\text { questions that are more challenging. }\end{array}$ \\
\hline Level 2 & $21-40$ & $\begin{array}{l}\text { This student has limited success with challenging content } \\
\text { on the FCAT. }\end{array}$ \\
\hline Level 1 & $1-20$ & $\begin{array}{l}\text { This student has little success with challenging content } \\
\text { on the FCAT. }\end{array}$ \\
\hline
\end{tabular}

Lastly, SPSS 20 software was used to analyze data about a potential correlation. With this tool, results were expected to be more accurate and efficient, with less human error.

The hypotheses of this study, therefore, are stated as follows:

Ho: There is no correlation between morphological awareness and reading comprehension.

Ha: There is a significant correlation between morphological awareness and students' reading comprehension.

\section{FINDINGS AND DISCUSSION}

\section{Findings}

\section{Results of the Morphological Awareness Test}

As stated earlier, morphological awareness test used in this study consists of items on morpheme identification and morphological structural awareness. The results of the test were tabulated in Table 2.

For morpheme identification test, there were five students who failed to reach the score above 70 . The rest of the students managed to do well by scoring more than 79 . There were 34 students who got 80 and 18 students got impressively full mark, which is 100 points. The average score for this test was 85.45. This result implies that $94 \%$ of students were able to solve the test very satisfactorily. 
The results of morphological structural awareness test also varied. With a total of 20 questions, this test was expected to be more difficult than the morpheme identification test. For this test, three students failed to get a score above 70 with two of them scoring lower than 50 . There were one and six students who scored 70 and 75 respectively. Five students got a pass with 80 points, and 13 students secured 85 points. Eight students out of 55 managed to get 90 points. Unfortunately, 13 students got one wrong answer from the total of 20 questions and therefore they scored 95. Lastly, the rest of the five students obtained the full score of 100 points.

Overall, the students achieved good results on the morphological awareness test which can be seen from the mean score of 85.32. It indicates that at least $85 \%$ of the students managed to answer the test satisfactorily.

Table 2. Results of Morphological Awareness Test

\begin{tabular}{|c|c|c|c|}
\hline $\begin{array}{c}\text { Number of } \\
\text { students }\end{array}$ & $\begin{array}{l}\text { Morpheme } \\
\text { Identification } \\
\text { Test (MIT) } \\
\text { score }\end{array}$ & $\begin{array}{c}\text { Number of } \\
\text { students }\end{array}$ & $\begin{array}{l}\text { Morpheme Structural } \\
\text { Awareness Test } \\
\text { MSAT) score }\end{array}$ \\
\hline 3 Students & 60 & 2 Students & 40 \\
\hline 34 Students & 80 & 1 Student & 60 \\
\hline 18 Students & 100 & 1 Student & 65 \\
\hline & & 1 Student & 70 \\
\hline & & 6 Students & 75 \\
\hline & & 5 Students & 80 \\
\hline & & 13 Students & 85 \\
\hline & & 8 Students & 90 \\
\hline & & 13 Students & 95 \\
\hline & & 5 Students & 100 \\
\hline Mean & 85.45 & Mean & 85.18 \\
\hline \multicolumn{4}{|c|}{ MIT mean score (85.45) + MSAT score 85.18) = 85.32 } \\
\hline \multicolumn{4}{|c|}{ Morphological awareness result is $\mathbf{8 5 . 3 2}$} \\
\hline
\end{tabular}




\section{Results of the Florida Comprehensive Assessment Test (FCAT)}

To determine the students' reading comprehension scores, the Florida Comprehensive Assessment Test (FCAT), as proposed by Foresman (2001), was applied. This test consists of four texts with five questions for each text. The results of this test revealed that the questions with the most incorrect answers were mostly literary analysis-related questions. Question no. 19, for example, was the question that received the most incorrect answers. Thirty eight students failed to answer this question correctly. Thirty-three students also failed to provide correct answers for Question no. 11. The third most incorrectly-answered question was Question no. 3; 23 students answered this question incorrectly. As mentioned previously, these three questions were literary analysis-related questions, asking about literary elements, such as plot development, setting, character development, character point of view, theme, conflict, resolution, etc. Question no. 3, for example, was What happened before the dog began running? This question was related to the plot of the story in the text and therefore involved literary elements.

Furthermore, 22 students seemed to have problems with Question no. 13, as they answered this question incorrectly. This question asked about the meaning of a word from a sentence in the story. The question was, What does "chattered" mean? This was a vocabulary context question. Other questions on the test also asked about vocabulary, specifically Question no. 4, Question no. 7, and Question no. 20. The number of participants who answered these three questions wrong varied. Twenty-three participants answered Question no.4 wrong, five participants answered Question no. 7 wrong, and lastly, 13 participants gave a wrong answer to Question no. 20.

The results of the FCAT test also showed that the lowest score was 35 and the highest score was 100 (a perfect score). Ten students received scores lower than 60, while one student received 100 points. The rest of the scores varied. One student barely reached the 60 mark with a score of 60 , three students obtained 65 points, one student obtained a score of 70 , six students obtained a score of 75,14 students received scores of 80 points, nine students obtained 85 points, and lastly, ten students scored 90 points. Overall, the mean score for the FCAT was 74.7.

As can be seen in Table 3 below, the results of the FCAT showed that 20 students were able to reach Achievement Level 5. Out of these students, one managed to answer all the questions correctly and obtained a perfect score. 
This indicates that these 21 students had success with the challenging content of the FCAT and that they were able to demonstrate high proficiency in the areas of vocabulary context, reading application, and literary analysis. The other 24 students had partial success with the challenging content of FCAT. They were likely to answer most of the questions correctly, but they still had some problems with the most challenging FCAT content. These students were placed at Achievement Level 4. The other seven students fell into a range of 41-60, which placed them at Achievement Level 3. These students may have answered many questions correctly, but had less success with the most challenging content of the FCAT. On the other hand, there were four students at Achievement Level 2. Being at this level means that these students had limited success with the challenging content of the FCAT in the areas of vocabulary context, reading application, and literary analysis.

Table 3.The Students' FCAT Achievement Levels

\begin{tabular}{ccc}
\hline No. & The level of FCAT & The number of students \\
\hline 1. & Level 5 & 20 students \\
\hline 2. & Level 4 & 24 students \\
\hline 3. & Level 3 & 7 students \\
\hline 4. & Level 2 & 4 students \\
\hline 5. & Level 1 & - \\
\hline
\end{tabular}

As mentioned previously, the mean score of the FCAT test was 74.7, which falls in the range of 61-80, and is categorized as Achievement Level 4 of the FCAT. Thus, it can be concluded that, in general, the students answered most of the questions correctly, but may have only had partial success with questions that reflected the most challenging content.

\section{Results of Pearson Correlation Coefficient}

As this research was intended to identify the relationship between morphological awareness and reading comprehension, SPSS 20 software was used to determine the Pearson Product-Moment Correlation coefficient to explore the relationship between these variables. The scores from the morphological awareness test and the reading comprehension test were entered into the application. The results are presented in Table 4. 
132 TEFLIN Journal, Volume 30, Number 1, January 2019

Table 4. Pearson Correlation between Morphological Awareness and Reading Comprehension

\begin{tabular}{lccc}
\hline \multicolumn{1}{c}{ Variables } & Means & Standard Deviation & $\begin{array}{c}\text { Pearson } \\
\text { Correlation }\end{array}$ \\
\hline Morphological awareness & 85.3 & 9.790 & \multirow{2}{*}{0.527} \\
\hline Reading comprehension & 74.7 & 16.114 & \\
\hline
\end{tabular}

The Pearson Correlation showed that the coefficient of correlation between students' morphological awareness and their reading comprehension was 0.527 , with a significance level of 0.01 . A significance level of 0.01 means that the percentage of validity of this calculation was $99 \%$. These results answered the main research question about the correlation between morphological awareness and reading comprehension, by showing that there is a significant correlation between morphological awareness and reading comprehension.

Furthermore, in order to find out if the hypothesis was accepted or rejected, we formulated the hypothesis as shown below:

- $\mathrm{Ho}=\rho=0,(\mathrm{Ho}=$ there is no correlation between morphological awareness and students' reading comprehension.)

- $\mathrm{Ha}=\rho>0,(\mathrm{Ha}=$ There is a strong correlation between morphological awareness and students' reading comprehension.)

The coefficient correlation was higher than $r$-table $(0.527>0.449)$. Therefore, the null hypothesis was rejected and the research hypothesis was accepted. This result leads to the conclusion that there is a significant correlation between morphological awareness and reading comprehension.

In determining to what extent these variables were correlated, we referred to the degree of correlation proposed by Jain and Aggarwal (2008, p. 8). Based on this proposed degree of correlation, $r=0.527$ falls in the range $0.40<\mathrm{KK}$ $\leq 0.70$. This indicates that the correlation between morphological awareness and reading comprehension is moderate, which means that students with a good understanding of morphological awareness will commonly receive good scores in reading. 
Aziz, Daud, \& Ismar, Morphological Awareness and EFL Reading 133

\section{Discussion}

The overall results of the test showed that the students could answer most of the questions correctly. Thus, on the whole they were placed at Achievement Level 4, with a mean score of 74.73. Generally, they demonstrated a good understanding of how to use context clues to determine the meaning of an unfamiliar word and showed very good ability in analyzing word structure (for example, prefixes, suffixes, and root words). Overall, they were able to identify a writer's main idea, purposes, and identify the structures/organization of a text.

The major finding from this study was that morphological awareness positively correlated with reading comprehension. The correlation was found to be 0.527 , with a significance level of 0.01 . The correlation was high enough to be a predictor in reading comprehension. These results were in accordance with the results of Nagy et al. (2006), in which a correlation of 0.59 was recorded, slightly higher than the correlation found in our study. In Nagy et al. (2006), morphological awareness was the strongest predictor of reading comprehension in grades four and five. The current study, however, focused on second-grade senior high school students whose ages ranged from 16-18. This factor is likely to be the cause of the different results between Nagy et al.'s (2006) study and the current study.

In addition, even though the level of correlation found in this study was classified as moderate, morphological awareness is still predicted to increase and contribute to reading comprehension. In line with this, Deacon et al.(2014)mention that morphological awareness supports students' reading comprehension through both a direct relationship and an indirect relationship. In so doing, it supports students by aiding them in understanding individual words which, in turn, supports reading comprehension. In accordance with this statement, it is safe to say that morphological awareness can help students understand complex words within a text.

\section{CONCLUSIONS}

To sum up, this research is a study about the correlation between morphological awareness and reading comprehension. There was a significant correlation between morphological awareness and reading comprehension found. The correlation was at a moderate level, 0.527 , with a significance level of 0.01 . This correlation coefficient is higher than the critical value of $r$-table 
$(0.527>0.449)$; therefore, the null hypothesis was rejected and the research hypothesis was accepted.

The findings of this study revealed that morphological awareness has the potential to be used as a strategy in reading comprehension. The correlation, which was categorized as moderate, showed that morphological awareness might contribute to reading comprehension. Teachers, therefore, should provide students with knowledge and instructions related to morphological awareness so that students can apply these skills while reading and when they find new words that might require a morphological analysis.

Lastly, because this is a correlational study and the data were collected within a short period of time, a causal relationship between the two variables cannot be assumed. Future longitudinal and experimental studies are recommended to shed more light on the possibility of causal influence. Studies concerning morphological awareness as a strategy in reading comprehension are also worthy of further investigation.

\section{REFERENCES}

Bae, H.S. (2016). Morphological awareness in reading comprehension: A secondary analysis. English Language Teaching, 28(3), 1-18.

Berninger, V.W., Abbott, R.D., Nagy, W., \& Carlisle, J.F. (2010). Growth in phonological, orthographic, and morphological awareness in grades 1 to 6 . Journal of Psycholinguistic Research, 39(2), 141-163.

Carlisle, J.F. (1995). Morphological awareness and early reading achievement. In L.B. Feldman (Ed.), Morphological aspects of language processing (pp.189-209). Hillsdale, NJ: Lawrence Erlbaum Associates.

Carlisle, J.F. (2000). Awareness of the structure and meaning of morphologically complex words: Impact on reading. Reading and Writing, 12(3), 169-190.

Carlisle, J.F., \& Fleming, J. (2003). Lexical processing of morphologically complex words in the elementary years. Scientific Studies of Reading, $7(3), 239-253$.

Chen, X., \& Schwartz, M. (2018). Morphological awareness and literacy in second language learners: A cross-language perspective. Reading and Writing, 31(8), 1685-1694.

Curinga, R. (2014). The effect of morphological awareness on reading comprehension: A study with adolescent Spanish-English emergent 
bilinguals.(Unpublished doctoral dissertation, The City University of New York, New York, USA). Retrieved from CUNY Academic Works, https://academicworks.cuny.edu/gc etds/30.

Deacon, S.H., Benere, J., \& Pasquerella, A. (2013). Reciprocal relationship: Children morphological awareness and their reading accuracy across grade 2 to 3. Developmental Psychology, 49(6), 1113-1126.

Deacon, S.H., Kieffer, M.J., \& Laroche, A. (2014). The relation between morphological awareness and reading comprehension: Evidence from mediation and longitudinal models. Scientific Studies of Reading,18(6), 432-451.

Deacon, S.H. \& Kirby, J.R. (2004). Morphological awareness: "Just more phonological?" The roles of morphological and phonological awareness in reading development. Applied Psycholinguistics, 25(2), 223-238.

Foresman, S. (2001). FCAT practice workbook. White Plains, NY: Addison Wesley Longman.

Goodwin, A.P., Huggins, A.C., Carlo, M.S., August, D., \& Calderon, M. (2013). Minding morphology: How morphological awareness relates to reading for English language learners. Reading and Writing, 26(9), 13871415 .

Harvey, S., \& Goudvis, A. (2007). Strategies that work: Teaching comprehension for understanding and engagement. Portsmouth, NH: Stenhouse Publishers.

Jain, T.R., \& Aggarwal, S.C. (2008). Statistics analysis for BBA. New Delhi: V. K. Publications.

Jarmulowicz, L. Hay, S.E., Taran, V.L., \& Ethington, C.A. (2008). Fitting derivational morphophonology into a developmental model of reading. Reading and Writing, 21(3), 275-297.

Kieffer, M., Biancarossa, G., \& Manchilla-Martinez, J. (2013). Roles of morphological awareness in English reading comprehension for Spanishspeaking language minority learners: Exploring partial mediation by vocabulary and reading fluency. Applied Psycholinguistics, 34(4), 677725 .

Kieffer, M., \& Box, C. D. (2013). Derivational morphological awareness, academic vocabulary, and reading comprehension in linguistically diverse sixth graders. Learning and Individual Differences, 24, 168-175. 
Kuo, L.-J., \& Anderson, R.C. (2006). Morphological awareness and learning to read: A cross-language perspective. Educational Psychologist, 41(3), 161180.

McBride-Chang, C., Wagner, R.K., Muse, A., \& Chow, B.W.-Y. (2005). The role of morphological awareness in children's vocabulary acquisition in English. Applied Psycholinguistics, 26(3), 415-435.

Nagy, W., Berninger, V.W., \& Abbot, R.D. (2006). Contributions of morphology beyond phonology to literacy outcomes of upper elementary and middle-school students. Journal of Educational Psychology, 98(1), 134.

Nurhemida. (2007).The relationship between morphological awareness and English vocabulary knowledge of Indonesian senior high school students. (Master's thesis, The University of Queensland, Brisbane, Australia). Retrieved from https://www.asian-efl-journal.com/Thesis/ThesisNurhemida.pdf

Schmitt, N. (2000). Vocabulary in language teaching. Cambridge: Cambridge University Press.

Wang, M., Cheng, C., \& Chen, S.-W. (2006). Contribution of morphological awareness to Chinese-English biliteracy acquisition. Journal of Educational Psychology,98(3),542-553.

Windsor, J. (1994). Children's comprehension and production of derivational suffixes. Journal of Speech and Hearing Research,37(2), 408-417.

Zhang, D., \& Koda, K. (2013). Morphological awareness and reading comprehension in a foreign language: A study of young Chinese EFL learners. System, 41(4), 901-913.

Zhang, D., Koda, K., \& Sun, X. (2014). Morphological awareness in biliteracy acquisition: A study of young Chinese EFL readers. International Journal of Bilingualism, 18(6) 570-585. 